DR EMMA FLANAGAN (Orcid ID : 0000-0002-3911-4780)

DR GREGORY MOORE (Orcid ID : 0000-0002-3689-8858)

DR MILES P SPARROW (Orcid ID : 0000-0003-2527-8044)

PROFESSOR MICHAEL A KAMM (Orcid ID : 0000-0003-3319-7199)

DR BRITT CHRISTENSEN (Orcid ID : 0000-0002-8746-4275)

DR OLGA NIEWIADOMSKI (Orcid ID : 0000-0003-3476-0422)

DR MARK G WARD (Orcid ID : 0000-0002-2840-0108)

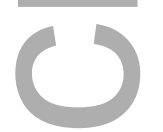

Article type :Original Scientific Paper

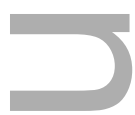

Infliximab, Adalimumab and Vedolizumab Concentrations Across Pregnancy and Vedolizumab Concentrations in Infants Following Intrauterine Exposure (

Short title: Biologic Levels in Pregnancy and Infant Vedolizumab Levels

\title{
Authors
}

Emma Flanagan

St Vincent's Hospital, Melbourne Australia; The University of Melbourne, Australia

Peter R Gibson

The Alfred Hospital, Melbourne, Australia; Monash University, Melbourne, Australia

Emily K Wright

St Vincent's Hospital, Melbourne Australia; The University of Melbourne, Australia

\section{Gregory T Moore}

This is the author manuscript accepted for publication and has undergone full peer review but has not been through the copyediting, typesetting, pagination and proofreading process, which may lead to differences between this version and the Version of Record. Please cite this article as doi: $10.1111 /$ APT.16102

This article is protected by copyright. All rights reserved 
Monash Health, Melbourne, Australia; Monash University, Melbourne, Australia

Miles P Sparrow

The Alfred Hospital, Melbourne, Australia; Monash University, Melbourne, Australia

William Connell

St Vincent's Hospital, Melbourne, Australia

Michael A Kamm

St Vincent's Hospital, Melbourne Australia; The University of Melbourne, Australia

Jakob Begun

Mater Hospital, Brisbane, Australia; Mater Research Institute, Brisbane, Australia

Britt Christensen

The Royal Melbourne Hospital, Melbourne, Australia

Peter De Cruz

Austin Health, Melbourne, Australia; The University of Melbourne, Australia

Edward Shelton

Monash Health, Melbourne, Australia

Damian Dowling

Barwon Health, Geelong, Australia

Jane M Andrews

Royal Adelaide Hospital, Adelaide, Australia

Steven J Brown

St Vincent's Hospital, Melbourne, Australia

This article is protected by copyright. All rights reserved 
Olga Niewiadomski

Eastern Health, Melbourne, Australia

Mark Ward

The Alfred Hospital, Melbourne, Australia; Monash University, Melbourne, Australia

Ourania Rosella

Monash University, Melbourne, Australia

Gennaro Rosella

Monash University, Melbourne, Australia

Katerina V Kiburg

St Vincent's Hospital, Melbourne, Australia; The University of Melbourne, Australia

Alyson L Ross

St Vincent's Hospital, Melbourne, Australia

Sally J Bell

St Vincent's Hospital, Melbourne, Australia; Monash Health, Melbourne, Australia

The PICCOLO Study Group

Address for correspondence:

Dr Emma Flanagan

Department of Gastroenterology, St Vincent's Hospital Melbourne

35 Victoria Parade, Fitzroy, Australia 3065

Phone: +61392313580

Fax: +61392313590

Email: emma.flanagan@svha.org.au

Word count: 4159

This article is protected by copyright. All rights reserved 


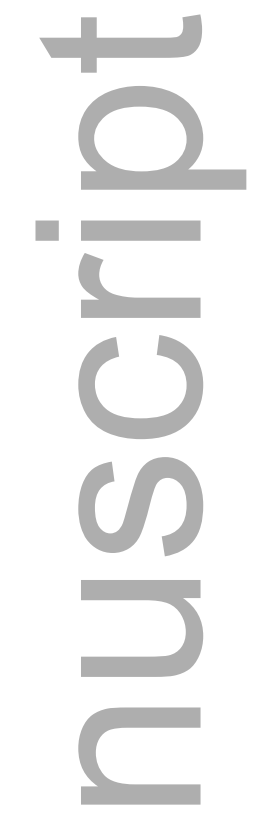

\section{Acknowledgements}

\section{Funding:}

This work was supported by the Departments of Gastroenterology at St Vincent's Hospital Melbourne, Australia and Monash University, Alfred Hospital (Melbourne, Australia), a research grant from The Gutsy Group Foundation, Australia and an Australian Government Research Training Program Scholarship (EF).

\section{Authorship Statement:}

Emma Flanagan contributed to the design of the study, acquisition and interpretation of data and drafted the manuscript. Peter Gibson contributed to the interpretation of data and critical revision of the manuscript. Emily Wright, Gregory Moore, Miles Sparrow, William Connell, Michael Kamm, Jakob Begun, Britt Christensen, Peter De Cruz, Edward Shelton, Damian Dowling, Jane Andrews, Steven Brown, Olga Niewiadomski, Mark Ward, Ourania Rosella and Gennaro Rosella contributed to the acquisition of data and critical revision of the manuscript. Katerina Kiburg contributed to the statistical analysis and interpretation of data. Alyson Ross contributed to the acquisition of data. Sally Bell contributed to the 
conception and design of the study, acquisition and interpretation of data and critical revision of the manuscript. All authors approved the final manuscript, including the authorship list. Emma Flanagan is the guarantor of this article.

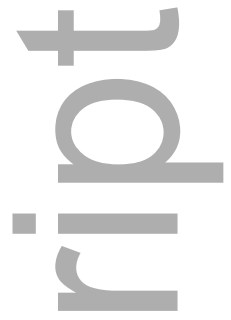

\section{Conflicts of interest:}

Emma Flanagan has received speaker's fees or educational grants from Ferring and Abbvie. Peter Gibson has served on the advisory boards of Janssen, Merck, Allergan, Pfizer and Takeda. His institution has received consultation fees from Janssen, Merck, Allergan, Pfizer and Takeda, has received research grants for other investigatordriven studies/clinical trial funding from AbbVie, Merck, A2 Milk Company, and speaker's fees from Janssen, Pfizer and Shire. Miles Sparrow has received educational grants or research support from Ferring, Orphan and Gilead; speaker's fees from Janssen, Abbvie, Ferring, Takeda, Pfizer and Shire; and served on advisory boards for Janssen, Takeda, Pfizer, Celgene, Abbvie, MSD and Emerge Health. Jakob Begun has served on the advisory board for Takeda and received speaking honorarium from Takeda. Peter De Cruz has served as a consultant, an advisory board member, or a speaker for AbbVie, Baxter, Ferring, Janssen, Shire and Takeda, and received research support from Ferring, Shire, Janssen, AbbVie and Takeda. Edward Shelton has received consultancy fees from Janssen. Jane Andrews has received speaker's fees, educational meeting co-ordination, research support or served on advisory boards for Abbott, AbbVie, Allergan, AstraZeneca, Bayer, Celegene, Ferring, Gilead, Hospira, ImmunsanT, Janssen, MSD, Nestle, Pfizer, Shire, Takeda, Sandoz, Vifor and Novartis. Sally Bell has received consultation fees from AbbVie and Janssen, has received research grants for other investigator-driven studies/clinical trial funding from AbbVie, Janssen, and Shire, and has received speaker's fees from AbbVie and Janssen. The remaining authors disclose no conflicts. 


\section{Summary}

Background: The impact of pregnancy on biologic levels in patients with IBD is undefined and time to elimination in vedolizumab-exposed infants is unknown.

Aims: To determine the effect of pregnancy on infliximab, adalimumab and vedolizumab drug levels and to study infant vedolizumab clearance.

Methods: In a prospective observational study, maternal drug levels were measured preconception, in each trimester, at delivery and postpartum and the association between drug levels and gestation in weeks was assessed using generalised estimating equation modelling. Infant vedolizumab levels were performed at birth (cord blood), six weeks and three months or until undetectable.

Results: 50 IBD patients ( 23 on infliximab, 15 on adalimumab, 12 on vedolizumab) with at least two intrapartum observations, plus 5 patients on vedolizumab with only mother and baby samples at delivery were included. Modelling showed no change in adalimumab levels, an increase in infliximab levels of $0.16(95 \% \mathrm{Cl} 0.08-0.24) \mu \mathrm{g} / \mathrm{L} /$ week $(p<0.001)$ and a decrease of 0.18 (95\% Cl: $-0.33--0.02) \mu \mathrm{g} / \mathrm{L} /$ week ( $p=0.03)$ for vedolizumab. In 17 motherbaby pairs, median infant vedolizumab levels at birth were lower than maternal levels $(p<0.05)$ with an infant:maternal ratio of 0.7 (IQR 0.5-0.9). Vedolizumab was undetectable between 15-16 weeks of age in all 12 infants completing follow-up testing.

Conclusions: During pregnancy, adalimumab levels remain stable, while infliximab levels increase and vedolizumab levels decrease. However, the increments were small suggesting intrapartum therapeutic drug monitoring and dose-adjustment are not indicated. Unlike infliximab and adalimumab, infant vedolizumab levels are lower in cord blood than in mothers and appear to clear rapidly.

Keywords: Inflammatory bowel disease, Pregnancy, Clinical Pharmacology

\section{Introduction}

Infliximab and adalimumab are anti-TNF monoclonal antibodies and vedolizumab is a newer anti-integrin monoclonal antibody. These biologic drugs are used to both induce and maintain remission in inflammatory bowel disease (IBD). During pregnancy, exposure to anti-TNF therapy is not associated with increased rates of adverse pregnancy outcomes ${ }^{1}$. Data relating to vedolizumab during pregnancy are currently more limited, but its risk is also 
considered low ${ }^{2,3}$. This is in contrast to active disease in pregnancy, which can be associated with adverse outcomes including pre-term birth and low birth weight ${ }^{4}$. Biologic drugs including anti-TNF therapy and more recently vedolizumab therefore form an integral part of IBD treatment during pregnancy.

As immunoglobulin $\mathrm{G1}$ ( $\operatorname{IgG1}$ ) antibodies, anti-TNF agents are actively transferred across the placenta via the Fc receptor in an exponential fashion from the mid second trimester of pregnancy ${ }^{5}$. Vedolizumab, also an IgG1 antibody, is assumed to have the same transfer characteristics. The pharmacodynamics and pharmacokinetics of many drugs are altered during pregnancy. One small study has documented anti-TNF drug levels in pregnant IBD patients. In this study, by Seow et al, including fifteen women who received infliximab and ten women treated with adalimumab, it was observed that infliximab levels increased during pregnancy while adalimumab levels remained stable ${ }^{6}$. Maternal vedolizumab drug levels throughout pregnancy are unknown.

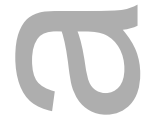

Cord blood concentrations and clearance patterns of anti-TNF agents in infants following intrauterine exposure have previously been studied ${ }^{7,8}$. The infant:maternal ratio of infliximab is higher and the infant clearance time of infliximab is longer than they are for adalimumab ${ }^{7,8}$. The placental transfer and clearance time in vedolizumab-exposed infants has not yet been established.

Although current data suggest there is no need to reduce these medications in pregnancy, the paucity of long term data results in a commonly expressed desire to minimise infant exposure where possible without compromising maternal disease control. Hence, we aimed to advance our understanding of the pharmacokinetics of infliximab, adalimumab and vedolizumab by measuring these drug levels across pregnancy, in order to inform optimal intrapartum dosing. Secondly, we aimed to evaluate the placental transfer, time to elimination, and short-term infant outcomes following intrauterine exposure to vedolizumab. 


\section{Materials and Methods}

\section{Study design and population:}

A prospective observational study was performed in women with a confirmed diagnosis of IBD who were either planning a pregnancy or were pregnant and on infliximab, adalimumab or vedolizumab. Patients were referred to the IBD and Pregnancy service at St Vincent's Hospital Melbourne, Australia between August 2017 and October 2019, from public hospital IBD clinics and private specialists across Australia.

\section{Study procedures:}

Peripheral blood was drawn from patients to measure maternal anti-TNF and vedolizumab levels pre-conception (up to 12 months), in each trimester of pregnancy, at delivery and postpartum (up to six months) where possible. Maternal infliximab and vedolizumab levels were measured at trough and adalimumab levels at steady state ${ }^{9,10}$. Results were excluded from the analysis of maternal levels across pregnancy when observations were not representative of trough or steady state levels, for example if participants had adjusted dosing to facilitate a break in therapy prior to delivery.

For participants treated with vedolizumab, umbilical cord blood and infant peripheral blood samples were taken at birth with further samples at approximately six weeks and three months, or until vedolizumab drug levels were undetectable. Maternal vedolizumab levels were measured at delivery to correlate with infant levels.

Clinical data relevant to pregnancy outcomes were recorded including IBD-related medical history, obstetric history, medication history, disease activity during pregnancy based on Physician Global Assessment (PGA), smoking and alcohol use during pregnancy and pregnancy complications. For participants on anti-TNF therapy, patient body mass index (BMI), serum albumin, C-reactive protein (CRP) and faecal calprotectin in each trimester were collected where possible and co-therapy with a thiopurine was documented. Baseline data were collected pre-conception when possible, and in the case of a patient being recruited to the study when already pregnant, available baseline and pre-conception data were collected at the time of recruitment. Dosing and timing of anti-TNF and vedolizumab therapy were at the discretion of the treating physician, not based on drug levels. Some 
participants on infliximab or vedolizumab had two levels measured within one trimester depending on the timing of infusions.

Pregnancy outcomes including mode of delivery, gestational age, neonatal birth weight, congenital anomalies and APGAR scores were recorded for all participants. Infant outcomes were documented by participant-reported questionnaires at six weeks and three months for infants exposed to vedolizumab in utero, including infant growth, infections, chronic medical conditions, allergies and adverse reactions to vaccinations.

\section{Laboratory methods:}

Serum was extracted from blood samples by centrifugation and frozen in aliquots at $-20^{\circ} \mathrm{C}$ until assays were performed at Monash University Department of Gastroenterology, Alfred Health, Australia. Serum adalimumab and infliximab concentrations were measured by enzyme linked immunosorbent assay (ELISA) using the Q-INFLIXI and Q-ADA, Matriks Biotek, Ankara, Turkey kits according to the manufacturer's instructions. Samples were tested in duplicate and the average expressed as $\mu \mathrm{g} / \mathrm{mL}$ serum. The coefficient of variation between assay wells was $<10 \%$. In case of very high concentrations, the sample was retested in different dilutions. In case of variation between the two results, a third analysis was performed. Serum vedolizumab levels were measured by ELISA using either the LisaTracker (Theradiag, France) or Ridascreen (R-Biopharm AG, Germany). The lower limit of detection was $2 \mu \mathrm{g} / \mathrm{mL}$ for the Lisa-Tracker Vedolizumab kit and $0.25 \mu \mathrm{g} / \mathrm{mL}$ for the Ridascreen kit. In-house testing of the two vedolizumab kits yielded similar results.

A minority of samples were sent to external laboratories for quantitative analysis of antiTNF drug levels, where other commercially available ELISA (Promonitor (Grifols, Spain)) or Lisa-Tracker (Theradiag, France)) were used, amongst which good correlation has been reported ${ }^{11-14}$.

\section{Statistical analysis:}

Data are reported as median [interquartile range (IQR)] or number (\%). Between group differences were compared by $\chi 2$ test, Fisher's exact test and Wilcoxon rank-sum test, as appropriate and for continuous variables with more than two categories the Kruskal-Wallis 
test was used. The Wilcoxon sign rank was used to compare drug levels between two time points. The association between biologic drug levels during pregnancy and gestation in weeks was assessed using a generalised estimating equation (GEE) for each drug (infliximab, adalimumab and vedolizumab). A GEE model was selected in order to account for longitudinal within-subject correlations ${ }^{15}$. An exchangeable covariance matrix was specified in order to control for adjustment for dependencies between repeated observations within individual participants. The models also specified robust errors. The effect of clinical parameters including maternal BMI, CRP, serum albumin and combination therapy on antiTNF levels was also examined, and those that were found to be significantly associated were added to the respective multivariable GEE model. Where CRP or faecal calprotectin were reported as a level below normal such as $<5$, a fixed number such as 4.9 was used in the analysis. Statistical analysis was performed using STATA version 16.1 (STATA LP College Station, TX, USA). A p value $\leq 0.05$ was considered statistically significant.

\section{Ethical considerations:}

Ethical approval for the study was obtained from the Human Research Ethics Committees at St Vincent's Hospital Melbourne (HREC/17/SVHM/116) and participants provided written informed consent before inclusion.

\section{Results}

50 patients ( 23 on infliximab, 15 on adalimumab, 12 on vedolizumab) with at least two observations in pregnancy (trimester one to delivery) while on stable dosing were included for analysis of maternal levels. A further five patients on vedolizumab had mother-baby paired samples for vedolizumab levels at delivery (total mother-baby paired levels $n=17$ ). Patient demographics are shown in Table 1. Patients on vedolizumab more commonly had a diagnosis of ulcerative colitis (UC) and were more likely to have active disease in pregnancy than women on anti-TNF therapy $(p<0.02)$.

\section{Infliximab cohort ( $n=23)$ :}

Infliximab was administered 6-8 weekly at a dose of $5 \mathrm{mg} / \mathrm{kg}$ in 21 patients, while one received 4-weekly dosing and another patient $10 \mathrm{mg} / \mathrm{kg}$. The last intrapartum dose was 
given at a median 31 (IQR 29-33) weeks. Individual trough infliximab levels including delivery levels (if representative of trough levels) are shown in Figure 1.

All participants on infliximab were in remission according to the Physician Global Assessment at the time of trough level measurements except for one. This participant, on 4weekly infliximab, had persistently elevated faecal calprotectin from pre-conception to postpartum, with a faecal calprotectin up to $1400 \mu \mathrm{g} / \mathrm{g}$ in the third trimester. Another participant, on 6-weekly dosing, had mildly active disease in the first trimester, prior to inclusion in the study. One other participant, who elected to cease her infliximab at 24 weeks gestation, experienced recurrence of her perianal fistulising Crohn's disease postpartum (infliximab levels following adjusted therapy not included).

For the patients on infliximab, the median available BMI, CRP and faecal calprotectin levels showed no significant difference between trimesters one to three $(p>0.05)$, although there was a numerical increase in BMI. Median albumin levels decreased from $36.0 \mathrm{~g} / \mathrm{L}(\mathrm{n}=17)$ in trimester one, to $30.5 \mathrm{~g} / \mathrm{L}(\mathrm{n}=26)$ in trimester two and fell to $28.0 \mathrm{~g} / \mathrm{L}(\mathrm{n}=21)$ in trimester three $(p<0.001)$.

The median number of trough levels per patient was 4 (range 2-6). Median infliximab trough levels were stable overall (Table 2, Figure 2). There were no significant differences in paired levels in trimester one (median 8.8, IQR 5.5-12.4 $\mathrm{gg} / \mathrm{mL}$ ) compared to trimester two (median 10.0, IQR 7.1-13.7 $\mu \mathrm{g} / \mathrm{mL}$ ), trimester two compared to trimester three (median 11.0, IQR 7.1-16.8 $\mu \mathrm{g} / \mathrm{mL}$ ) or trimester one compared to trimester three (all $p>0.05$, Wilcoxon). There was no significant difference in the median number of weeks between infusions (eight weeks) at each trimester $(p=0.77)$.

There was, however, a small but statistically significant increase observed in infliximab level by gestational week when modelled using a generalised estimating equation, with a univariate regression coefficient of $0.16(95 \% \mathrm{Cl} 0.08-0.24, \mathrm{p}<0.001)$. This positive association between infliximab levels and gestational week remained significant in 
multivariable models following the individual addition of BMI, albumin, CRP or concomitant thiopurine therapy.

\section{Adalimumab cohort ( $n=15)$ :}

Thirteen patients were on adalimumab fortnightly and two were on weekly dosing. Two patients were commenced on adalimumab in pregnancy at least 12 weeks before the earliest adalimumab level. Ten patients continued adalimumab throughout pregnancy and five stopped at 30-33 weeks. The last intrapartum dose was given at a median 37 (IQR 3138) weeks.

All patients on adalimumab were in remission according to PGA at the time of included drug levels. One patient had a faecal calprotectin of $453 \mu \mathrm{g} / \mathrm{g}$ in trimester one, which subsequently normalised and she remained clinically well. Another patient, who was switched from infliximab to adalimumab in the second trimester due to anti-drug antibodies, had a severe postpartum flare in the setting of a postpartum adalimumab level of $0.73 \mu \mathrm{g} / \mathrm{mL}$ (postpartum result excluded in the setting of loss of response to anti-TNF; the participant previously had therapeutic adalimumab levels and was well throughout pregnancy).

For the patients on adalimumab, the median available BMI, CRP and faecal calprotectin levels showed no significant difference across trimesters one to three ( $p>0.05)$, although there was a numerical increase in BMI. Median albumin levels decreased from $33.5 \mathrm{~g} / \mathrm{L}$ $(n=8)$ in trimester one, to $30.0 \mathrm{~g} / \mathrm{L}(\mathrm{n}=12)$ in trimester two and fell to $27.0 \mathrm{~g} / \mathrm{L}(\mathrm{n}=15)$ in trimester three $(p=<0.001)$.

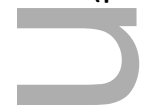

Individual adalimumab levels including delivery levels that were reflective of steady-state (with no break in therapy prior to delivery) are shown in Figure 3. The median number of adalimumab levels per patient was 3 (range 2-6). Median adalimumab levels were stable across pregnancy (Table 3, Figure 4). There were no significant differences in paired levels in trimester one (median 5.7, IQR 4.8-10.2 $\mathrm{gg} / \mathrm{mL}$ ) compared to trimester two (median 5.2, 
IQR 4.0-6.8 $\mu \mathrm{g} / \mathrm{mL}$ ), trimester two compared to trimester three (median 5.8, IQR 4.8-8.0 $\mu \mathrm{g} / \mathrm{mL}$ ) or trimester one compared to trimester three (all $\mathrm{p}>0.05$, Wilcoxon).

No association was found between adalimumab levels and gestational weeks when modelled using a generalised estimating equation, with a regression coefficient of -0.01 (95\% Cl: $-0.10,0.09, p=0.90)$.

\section{Vedolizumab cohort ( $n=17)$ :}

Vedolizumab was administered at a dose of $300 \mathrm{mg}$, 8-weekly in fourteen patients and 4weekly in three patients. The last intrapartum dose was given at a median 30 weeks.

Of the 17 patients on vedolizumab, six experienced active disease during pregnancy, reflecting a more refractory and biologic-experienced cohort. One had active disease in early pregnancy while on 4-weekly dosing, two patients required prednisolone, one required antibiotics for perianal disease and another continued vedolizumab to 35 weeks gestation. Another patient had a severe flare requiring hospital admission for intravenous steroids and was subsequently re-commenced on vedolizumab at 14 weeks gestation; her vedolizumab trough levels were not included throughout pregnancy (only mother-baby paired samples at delivery).

In the 12 patients with at least two observations in pregnancy, maternal trough vedolizumab levels are shown in Table 4 and Figures 5 and 6 . The median number of intrapartum levels per patient $(n=12)$ was 3 (range $2-4)$. In one of the patients on 4-weekly dosing, vedolizumab was de-escalated to 8-weekly for the third trimester (following an atypical lower respiratory tract infection) and hence the subsequent trough levels were not included in the analysis of maternal levels across pregnancy for this patient. One other patient was commenced on vedolizumab at around three weeks' gestation, with steady state trough levels included from late in her second trimester of pregnancy. Vedolizumab levels were not representative of trough levels in the majority of participants at delivery and postpartum due to timing of the dose around delivery.

This article is protected by copyright. All rights reserved 
There were no significant differences in paired levels between trimester one (median 19.0, IQR 13.0-23.0) $\mu \mathrm{g} / \mathrm{mL}$ ) and trimester two (median 15.1, IQR 8.6-21.7 $\mu \mathrm{g} / \mathrm{mL}$ ), trimester two and trimester three (median 9.5, IQR 3.7-20.0 $\mu \mathrm{g} / \mathrm{mL}$ ) or trimester one and trimester three (all $p>0.05$, Wilcoxon).

However, there was a small but statistically significant decrease observed in vedolizumab level by gestational week when modelled using the generalised estimating equation, with a univariate regression coefficient of $-0.18(95 \% \mathrm{Cl}:-0.33--0.02, p=0.03)$.

\section{Placental transfer of vedolizumab ( $n=17)$ :}

The median infant vedolizumab level was 5.0 (IQR 2.5-7.1) $\mu \mathrm{g} / \mathrm{mL}$, which was lower than the median level in their mothers at delivery, $9.5($ IQR 3.0-13.0) $\mu \mathrm{g} / \mathrm{mL})(\mathrm{p}<0.05)$. The median infant to maternal vedolizumab ratio was 0.7 (IQR 0.5-0.9). There was a strongly positive correlation between infant vedolizumab levels and maternal vedolizumab levels at delivery $(r=0.91, p<0.001)$ (Figure 7). The time since last intrapartum dose inversely correlated with infant vedolizumab levels at delivery $(r=-0.79, p<0.001)$ (Figure 8).

Individual infant vedolizumab levels at birth were all lower than their mother's, except in two infants with low cord blood levels; one infant had vedolizumab level of $2.5 \mu \mathrm{g} / \mathrm{mL}$ when the mother's delivery level was also low at $1.6 \mu \mathrm{g} / \mathrm{mL}$ and another infant had a vedolizumab level of $1.9 \mu \mathrm{g} / \mathrm{mL}$ when the maternal level was $1.6 \mu \mathrm{g} / \mathrm{mL}$ ).

\section{Vedolizumab time to clearance in infants:}

Vedolizumab was undetectable at 6-8 weeks of age in four infants, and at 10-15 weeks of age in another seven infants (Table 5). One infant, who was exposed to 4-weekly vedolizumab to 33 weeks gestation, had a vedolizumab level of $1.9 \mu \mathrm{g} / \mathrm{mL}$ at 12 weeks and an undetectable level at 16 weeks (Patient 12). Three infants had very low levels at 6-8 weeks of age and further blood testing was declined (Table 5). One participant declined all follow up blood testing after birth (Patient 13) and one infant remains in follow up testing (Patient 17). 


\section{Overall Pregnancy Outcomes:}

The majority of babies were delivered at full term with normal birthweight, showing rates similar to the population norms in Australia. Pregnancy outcomes are shown in Table 6. One infant exposed to vedolizumab was diagnosed with hip dysplasia at birth.

One participant on 6-weekly infliximab who had active UC in early pregnancy and placenta praevia underwent an elective caesarean at 36 weeks +5 days. One participant who was induced with vedolizumab in the second trimester due to active UC in pregnancy delivered at 34 weeks gestation following preterm premature rupture of membranes. Another participant on 4-weekly vedolizumab with chronic active colitis delivered at 35 weeks gestation after preterm premature rupture of membranes.

\section{Infant outcomes following intrauterine vedolizumab exposure up to three months of age} $(n=16)$ :

16 infants have completed follow up of infant outcomes to three months of age, while one baby remains in follow-up testing (Table 7). All babies were reported to be well at three months of age. Two infants had hip dysplasia; one diagnosed at birth (reported above), which resolved, and another diagnosed at three months in the setting of breech positioning and pre-term delivery. Another infant was diagnosed with a neck mass at around two weeks of age, which was improving and thought to be a submandibular gland on imaging; the infant was otherwise well. Two infants had a possible allergy to cow's milk-based formula.

\section{Discussion}

Therapeutic drug monitoring of biologic levels is increasingly used to optimise and guide therapy when clinical response is inadequate. Given the importance of maintaining an adequate clinical response during pregnancy, it is important to understand whether pregnancy impacts drug levels. In this prospective observational study, the effect of 
pregnancy was determined by longitudinal measurements of drug levels with utilisation of GEE modeling to gain an accurate understanding of the association between maternal levels and gestational week of pregnancy. For adalimumab, levels are stable in pregnancy whether examined by the median levels in each trimester or by modelling. In contrast, modelling indicates that infliximab levels can display a small increase, while maternal vedolizumab levels decreased through pregnancy. Additionally, this study examined the placental transfer and clearance time of vedolizumab following intrauterine exposure, showing that median vedolizumab levels in infants are lower than maternal levels and are cleared by sixteen weeks or earlier. Pregnancy and infant outcomes in this cohort, although small, appeared consistent with the background population.

The elimination of anti-TNF monoclonal antibodies, while predominantly linear, is subject to multiple physiological, drug-specific and disease-related factors that include changes in body weight and serum albumin concentrations, the development of anti-drug antibodies, the type of anti-TNF drug ${ }^{7}$, and more severe disease activity ${ }^{16,17}$. The marked physiological changes that occur in association with pregnancy might be anticipated to change the clearance of these drugs. The clearance of many drugs is known to be increased during pregnancy ${ }^{18}$, therefore lower drug levels may be expected. It is also possible that TNF $\alpha$ itself may be reduced during pregnancy ${ }^{19}$, resulting in less binding with anti-TNF antibodies and therefore increased levels of free drug might be seen.

Clearance of adalimumab in pregnancy, however, appears unchanged. Both the current study and that by Seow et al have shown that adalimumab levels are stable in pregnancy ${ }^{6}$. Meanwhile, infliximab levels increased in pregnancy, suggesting clearance appears mildly reduced for infliximab. Given the similarities between the two anti-TNF antibodies, this is somewhat unexpected. However, the data from Seow et al also supports our findings. In the previous report, median infliximab trough levels increased from $8.5 \mu \mathrm{g} / \mathrm{mL}$ in trimester one (5 included observations) to $21.0 \mu \mathrm{g} / \mathrm{mL}$ in trimester three (16 included observations), and logistic regression modelling suggested that, after adjusting for albumin, CRP and BMI, maternal infliximab levels increased by $4.2 \mu \mathrm{g} / \mathrm{mL}$ each trimester ${ }^{6}$. In contrast, in the present study that reports on a larger cohort with more complete longitudinal drug levels, 
no significant differences between median infliximab levels were observed in trimester one through trimester three. However, our modelling has shown a small but significant increase in infliximab levels of $0.16 \mu \mathrm{g} / \mathrm{mL}$ per gestational week, which is equivalent to an estimate of 4.8 $(95 \% \mathrm{Cl} 2.4-7.2) \mu \mathrm{g} / \mathrm{mL}$ over 30 weeks from the first measurement towards the end of the first trimester, assuming a constant linear rise in infliximab in pregnancy. This was not influenced by changes in albumin, CRP, BMI or concomitant thiopurine. The effect of a 4-5 $\mu \mathrm{g} / \mathrm{mL}$ increase in levels is unknown, but is unlikely to be associated with adverse effects ${ }^{20}$. While the direction of change seems similar, the more than two-fold greater increase in maternal infliximab levels found in the previous study compared with that in the current cohort may have reflected the lower numbers of observations in the earlier report.

In contrast to infliximab, median maternal vedolizumab levels tended to fall across pregnancy and modelling indicated a small but statistically significant decrease in vedolizumab levels per gestational week. This amounted to about the same rate of fall as the increase for infliximab. Evidence regarding an exposure-efficacy relationship is weaker with vedolizumab than infliximab ${ }^{21,22}$, therefore a small drop across pregnancy may not be clinically significant. As an IgG monoclonal antibody, pharmacokinetic properties of vedolizumab should be expected to be similar to the anti-TNF agents ${ }^{17}$. Vedolizumab exhibits a slower, linear elimination at levels above $10 \mu \mathrm{g} / \mathrm{mL}$, but rapid, saturable, nonlinear elimination at lower concentrations ${ }^{23}$. Clearance also appears increased with higher body weight and low albumin ${ }^{21,23}$. Although distribution is slower for adalimumab as it is subcutaneously injected, the distribution of monoclonal antibodies remains mainly within the plasma and extracellular fluid due to their large molecular size, with a relatively small volume of distribution ranging from approximately 3-6 $L$ for infliximab, adalimumab and vedolizumab ${ }^{23,24}$. During pregnancy, plasma volume increases by around $40-50 \%$, but, with their limited volume of distribution, the pharmacokinetics of monoclonal antibodies are not considered likely to be substantially altered ${ }^{24}$, despite other physiological adaptations in pregnancy such as the reduced albumin concentrations later in pregnancy. However, the current study suggests there may be pregnancy-related changes that marginally increase vedolizumab clearance in pregnancy. In contrast to the changes seen with infliximab and adalimumab, the increased clearance of vedolizumab during pregnancy observed in the 
current study appears more consistent with what might be the typical expectation of drug clearance change in pregnancy.

Our data show that median infant levels of vedolizumab at birth are lower than maternal levels. The median infant:maternal vedolizumab level ratio in 17 mother-baby pairs at delivery was 0.7 (IQR 0.5-0.9). Along with a possible decrease in maternal vedolizumab levels in pregnancy, this study suggests placental transfer of vedolizumab is less than with infliximab and adalimumab, for which the median infant:maternal ratios from the ERA study were 1.97 and 1.21, respectively ${ }^{7}$. Preliminary findings from our study were presented in a letter to the editor reporting the first five of these mother-baby pairs and time to clearance in three infants ${ }^{25}$. Our results relating to placental transfer of vedolizumab are consistent with two other smaller studies, including preliminary data from the ongoing Pregnancy in Inflammatory Bowel Disease and Neonatal Outcomes (PIANO) registry $(n=7)$ and another small case series from Denmark $(n=2)$, where infant vedolizumab levels at birth were also reported as lower than maternal levels ${ }^{26,27}$. Given that vedolizumab is also an IgG1 molecule, which is thought to be actively transported across the placenta in a similar way to infliximab and adalimumab, it is unclear why infant vedolizumab levels are lower than maternal levels. The expression of integrin receptors in the placenta is unknown but it is possible that vedolizumab remains bound within the placenta rather than transferring to the neonate.

A novel finding of our study is that vedolizumab levels are undetectable by sixteen weeks of age in exposed infants (median time to undetectable concentration of 10.5 weeks, range 816 weeks). The only previous report was of one baby from the Danish case series with a very low vedolizumab level of $0.10 \mu \mathrm{g} / \mathrm{mL}$ at six months of age ${ }^{26}$. Infant clearance time for antiTNF medications has previously been established, with a mean clearance time of 7.3 months for infliximab and 4.0 months following intrauterine adalimumab exposure ${ }^{7}$. In contrast, the current study has shown that vedolizumab was cleared at a median of 2.5 months (Table 5). Although vedolizumab has a longer half-life than infliximab and adalimumab, the rapid clearance in neonates may be in keeping with the known vedolizumab pharmacokinetic property of increased clearance at lower concentrations. 
There is some uncertainty regarding the safety of the live rotavirus vaccine following antenatal vedolizumab exposure, particularly given its gut-specific mode of action. In a small subset from the PIANO registry data, there were no serious adverse events reported in infants administered the rotavirus vaccine $(n=40)^{28}$. However, these data do not include vedolizumab-exposed infants ${ }^{28}$. Reassuringly, from our study to date it appears that in over $90 \%$ of babies vedolizumab is cleared by the recommended age limit at which the rotavirus vaccine can be given in Australia (fifteen weeks). Until further data regarding infant clearance time are available, if the rotavirus vaccine is to be given to vedolizumab-exposed infants we advocate for consideration of one serum vedolizumab level assessment prior to vaccine administration.

Limitations of the study include the potential variance in drug levels due to the use of ELISA kits from different sources for maternal infliximab and adalimumab levels. Previous studies ${ }^{11-14}$ and our own in-house evaluation (unpublished) show similar levels across the different assay kits. Small differences would be unlikely to significantly influence the results as the majority of intrapartum levels were measured using the Q-INFLIXI and Q-ADA assays, respectively. Paired mother and infant vedolizumab samples were performed using the same assay. Additionally, adalimumab levels were defined as steady-state rather than documented trough levels, as is widely practiced (including in the previous study by Seow et $a l)^{6,9}$. Nonetheless, we routinely advised trough adalimumab levels to be performed and the majority of intrapartum adalimumab levels were measured at trough; thus the effect of potential intra-patient variability in adalimumab levels was deemed to be minimal10,29. Another limitation of the study includes the small sample size, particularly for intrapartum vedolizumab levels and vedolizumab-exposed infants, although this is the largest study in the field to date and we have included more serial observations in each participant across pregnancy than previously described.

In conclusion, this longitudinal study indicates that biological drugs used in patients with IBD differ in their altered clearance profiles during pregnancy. Adalimumab levels remain stable in pregnancy, while there can be a small increase in infliximab levels and decrease in vedolizumab levels during pregnancy. However, the alterations in concentrations predicted 
are small and unlikely to be of clinical significance regarding efficacy or toxicity. Hence, routine therapeutic drug monitoring and intrapartum dosing adjustment are not indicated. Unlike anti-TNF monoclonal antibodies, infant vedolizumab levels are lower in cord blood than in mothers and are likely to be fully eliminated by sixteen weeks of age in infants following intrauterine exposure.

\section{References}

1. Shihab Z, Yeomans ND, De Cruz P. Anti-Tumour Necrosis Factor alpha Therapies and Inflammatory Bowel Disease Pregnancy Outcomes: A Meta-analysis. J Crohns Colitis. 2016;10(8):979-88.

2. Mahadevan U, Vermeire S, Lasch K, Abhyankar B, Bhayat F, Blake A, et al. Vedolizumab exposure in pregnancy: outcomes from clinical studies in inflammatory bowel disease. Aliment Pharmacol Ther. 2017;45(7):941-50.

3. Mahadevan U, McConnell RA, Chambers CD. Drug Safety and Risk of Adverse Outcomes for Pregnant Patients With Inflammatory Bowel Disease. Gastroenterology. 2017;152(2):451-62 e2.

4. Kammerlander H, Nielsen J, Kjeldsen J, Knudsen T, Friedman S, Norgard B. The Effect of Disease Activity on Birth Outcomes in a Nationwide Cohort of Women with Moderate to Severe Inflammatory Bowel Disease. Inflamm Bowel Dis. 2017;23(6):1011-8.

5. Malek A, Sager R, Kuhn P, Nicolaides KH, Schneider H. Evolution of Maternofetal Transport of Immunoglobulins During Human Pregnancy. Am J Reprod Immunol. 1996;36(5):248-55.

6. Seow CH, Leung Y, Vande Casteele N, Ehteshami Afshar E, Tanyingoh D, Bindra G, et al. The effects of pregnancy on the pharmacokinetics of infliximab and adalimumab in inflammatory bowel disease. Aliment Pharmacol Ther. 2017;45(10):1329-38.

7. Julsgaard M, Christensen LA, Gibson PR, Gearry RB, Fallingborg J, Hvas CL, et al. Concentrations of Adalimumab and Infliximab in Mothers and Newborns, and Effects on Infection. Gastroenterology. 2016;151(1):110-9.

8. Kanis SL, de Lima-Karagiannis A, van der Ent C, Rizopoulos D, van der Woude CJ. AntiTNF Levels in Cord Blood at Birth are Associated with Anti-TNF Type. J Crohns Colitis. 2018;12(8):939-47. 
9. Hendy P, Hart A, Irving P. Anti-TNF drug and antidrug antibody level monitoring in IBD: a practical guide. Frontline Gastroenterol. 2016;7(2):122-8.

10. Lie MR, Peppelenbosch MP, West RL, Zelinkova Z, van der Woude CJ. Adalimumab in Crohn's disease patients: pharmacokinetics in the first 6 months of treatment. Aliment Pharmacol Ther. 2014;40(10):1202-8.

11. Perez I, Fernandez L, Sanchez-Ramon S, Alba C, Zatarain A, Canas M, et al. Reliability evaluation of four different assays for therapeutic drug monitoring of infliximab levels. Therap Adv Gastroenterol. 2018;11:1756284818783613.

12. Neveu B, Kunst A, Prosser C, Robitaille R. An in vitro comparison of four different immunoassays for the monitoring of Infliximab biosimilars drug levels. Clin Biochem. 2020;78:58-62.

13. Malickova K, Duricova D, Bortlik M, Hind'os M, Machkova N, Hruba V, et al. Serum trough infliximab levels: A comparison of three different immunoassays for the monitoring of CT-P13 (infliximab) treatment in patients with inflammatory bowel disease. Biologicals. 2016;44(1):33-6.

14. Sam M, Ng W, Connor S, Toong C. Comparative evaluation of four commercially available ELISA kits for therapeutic drug monitoring of adalimumab. Poster session presented at: 16th International Congress of Therapeutic Drug Monitoring \& Clinical Toxicology; Sep 16-19; Brisbane, Australia 2018.

15. Zeger SL LK. Longitudinal data analysis for discrete and continuous outcomes. Biometrics. 1986:121-30.

16. Dotan I, Ron Y, Yanai H, Becker S, Fishman S, Yahav L, et al. Patient Factors That Increase Infliximab Clearance and Shorten Half-life in Inflammatory Bowel Disease. Inflamm Bowel Dis. 2014;20(12):2247-59.

17. Berends SE, Strik AS, Lowenberg M, D'Haens GR, Mathot RAA. Clinical Pharmacokinetic and Pharmacodynamic Considerations in the Treatment of Ulcerative Colitis. Clin Pharmacokinet. 2019;58(1):15-37.

18. Anderson GD. Pregnancy-induced changes in pharmacokinetics. Clinical pharmacokinetics. 2005 Oct 1;44(10):989-1008.

19. van der Giessen J, Binyamin D, Belogolovski A, Frishman S, Tenenbaum-Gavish K, Hadar E, et al. Modulation of cytokine patterns and microbiome during pregnancy in IBD. Gut. 2020;69(3):473-86. 
20. Gibson DJ, Ward MG, Rentsch C, Friedman AB, Taylor KM, Sparrow MP, et al. Review article: determination of the therapeutic range for therapeutic drug monitoring of adalimumab and infliximab in patients with inflammatory bowel disease. Aliment Pharmacol Ther. 2020;51(6):612-28.

21. Ward MG SM, Roblin X. Therapeutic drug monitoring of vedolizumab in inflammatory bowel disease: current data and future directions. Therap Adv Gastroenterol. 2018;11:1-10.

22. Pouillon L, Vermeire $S$, Bossuyt $P$. Vedolizumab trough level monitoring in inflammatory bowel disease: a state-of-the-art overview. BMC Med. 2019;17(1):89.

23. Rosario M, Dirks NL, Milch C, Parikh A, Bargfrede M, Wyant T, et al. A Review of the Clinical Pharmacokinetics, Pharmacodynamics, and Immunogenicity of Vedolizumab. Clin Pharmacokinet. 2017;56(11):1287-301.

24. Stone $\mathrm{RH}$, Hong J, Jeong H. Pharmacokinetics of Monoclonal Antibodies Used for Inflammatory Bowel Diseases in Pregnant Women. J Clin Toxicol. 2014;4(4).

25. Flanagan E, Gibson PR, Begun J, Ghaly S, Garg M, Andrews JM, Rosella O, Rosella G, Bell SJ. Letter: vedolizumab drug concentratimns in neonates following intrauterine exposure. Aliment Pharmacol Ther. 2018.

26. Julsgaard M, Kjeldsen J, Brock B, Baumgart DC. Letter: vedolizumab drug levels in cord and maternal blood in women with inflammatory bowel disease. Aliment Pharmacol Ther. 2018;48(3):386-8.

27. Mahadevan U, Martin C, Kane SV, Dubinsky M, Sands BE, Sandborn W. 437 Do infant serum levels of biologic agents at birth correlate with risk of adverse outcomes? Results from the PIANO registry. Gastroenterology. 2016;150(4):S91-S2.

28. Beaulieu DB, Ananthakrishnan AN, Martin C, Cohen RD, Kane SV, Mahadevan U. Use of Biologic Therapy by Pregnant Women With Inflammatory Bowel Disease Does Not Affect Infant Response to Vaccines. Clin Gastroenterol Hepatol. 2018;16(1):99-105.

29. Ward MG, Thwaites PA, Beswick L, Hogg J, Rosella G, Van Langenberg D, et al. Intrapatient variability in adalimumab drug levels within and between cycles in Crohn's disease. Aliment Pharmacol Ther. 2017;45(8):1135-45. 
Tables

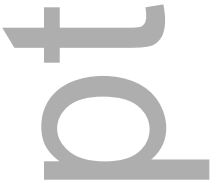

Table 1: Patient demographics

\begin{tabular}{|c|c|c|c|c|c|}
\hline \multicolumn{2}{|l|}{ Median (IQR) or n (\%) } & $\begin{array}{l}\text { Infliximab } \\
n=23\end{array}$ & $\begin{array}{l}\text { Adalimumab } \\
n=15\end{array}$ & $\begin{array}{l}\text { Vedolizumab } \\
n=17\end{array}$ & $\mathrm{p}$-value \\
\hline $\begin{array}{l}\text { Age at beginning of } \\
\text { pregnancy (years) }\end{array}$ & & $\begin{array}{l}32.3(28.8- \\
35.2)\end{array}$ & $\begin{array}{l}34.0(30.2- \\
36.7)\end{array}$ & $\begin{array}{l}30.7(27.8- \\
33.5)\end{array}$ & 0.43 \\
\hline $\begin{array}{l}\text { Weight prior to } \\
\text { pregnancy (kg) }\end{array}$ & & $\begin{array}{l}65.0(58.0- \\
73.0)\end{array}$ & $\begin{array}{l}70.0(65.0- \\
86.0)\end{array}$ & $\begin{array}{l}67.0(58.0- \\
81.0)\end{array}$ & 0.20 \\
\hline Diagnosis & $\begin{array}{l}\text { Crohn's } \\
\text { disease }\end{array}$ & 17 (74\%) & 14 (93\%) & $5(29 \%)$ & $<0.001$ \\
\hline & $\begin{array}{l}\text { Ulcerative } \\
\text { colitis }\end{array}$ & $4(17 \%)$ & $1(7 \%)$ & $12(71 \%)$ & \\
\hline & $\begin{array}{l}\text { IBD } \\
\text { Unclassified }\end{array}$ & $2(9 \%)$ & $0(0 \%)$ & $0(0 \%)$ & \\
\hline $\begin{array}{l}\text { Crohn's disease } \\
\text { location }\end{array}$ & Ileal & $7(30 \%)$ & $4(27 \%)$ & $2(12 \%)$ & 0.74 \\
\hline & Colonic & $5(22 \%)$ & $3(20 \%)$ & $2(12 \%)$ & \\
\hline & Ileocolonic & $5(22 \%)$ & 7 (47\%) & $1(6 \%)$ & \\
\hline $\begin{array}{l}\text { Crohn's disease } \\
\text { behaviour }\end{array}$ & $\begin{array}{l}\text { Non- } \\
\text { stricturing, } \\
\text { non- } \\
\text { penetrating }\end{array}$ & $8(35 \%)$ & $10(67 \%)$ & $3(18 \%)$ & 0.59 \\
\hline
\end{tabular}

This article is protected by copyright. All rights reserved 


\begin{tabular}{|c|c|c|c|c|c|}
\hline & Stricturing & $8(35 \%)$ & $4(27 \%)$ & $2(12 \%)$ & \\
\hline & Penetrating & $1(4 \%)$ & $0(0 \%)$ & $0(0 \%)$ & \\
\hline $\begin{array}{l}\text { Perianal Crohn's } \\
\text { disease }\end{array}$ & Yes & $6(26 \%)$ & $7(47 \%)$ & $4(19 \%)$ & 0.23 \\
\hline $\begin{array}{l}\text { Upper gastrointestinal } \\
\text { Crohn's disease }\end{array}$ & Yes & $1(4 \%)$ & $2(13 \%)$ & $1(6 \%)$ & 0.47 \\
\hline \multirow[t]{2}{*}{$\begin{array}{l}\text { Ulcerative colitis } \\
\text { location }\end{array}$} & E2 left-sided & $1(4 \%)$ & $0(0 \%)$ & $5(31 \%)$ & 0.73 \\
\hline & E3 pan-colitis & $5(22 \%)$ & $1(7 \%)$ & 7 (44\%) & \\
\hline $\begin{array}{l}\text { Disease duration at } \\
\text { start of pregnancy } \\
\text { (years) }\end{array}$ & & $8.0(6.9-14.1)$ & $8.6(4.1-12.6)$ & $11.6(7.9-14.2)$ & 0.30 \\
\hline $\begin{array}{l}\text { Duration anti-TNF at } \\
\text { start of pregnancy } \\
\text { (years) }\end{array}$ & & $2.2(1.6-4.5)$ & $1.4(0.8-3.8)$ & & 0.24 \\
\hline $\begin{array}{l}\text { Duration vedolizumab } \\
\text { at start of pregnancy } \\
\text { (years) }{ }^{\dagger}\end{array}$ & & & & $1.4(0.7-2.9)$ & \\
\hline $\begin{array}{l}\text { Anti-TNF therapy prior } \\
\text { to vedolizumab }\end{array}$ & & - & - & $12(71 \%)$ & \\
\hline $\begin{array}{l}\text { Active disease during } \\
\text { pregnancy according } \\
\text { to PGA }\end{array}$ & Yes & $2(9 \%)$ & $0(0 \%)$ & $6(35 \%)$ & 0.012 \\
\hline $\begin{array}{l}\text { Thiopurine during } \\
\text { pregnancy }\end{array}$ & Yes & $14(61 \%)$ & $9(60 \%)$ & $4(24 \%)$ & 0.044 \\
\hline
\end{tabular}

†In patients with intrapartum maternal vedolizumab levels ( $n=12$ ) 
IBD: inflammatory bowel disease; PGA: Physician global assessment

Table 2: Median infliximab levels across pregnancy $(n=23)$

\begin{tabular}{l|c|c|}
\hline & Number of observations & Median (IQR) infliximab level $(\mu \mathrm{g} / \mathrm{mL})$ \\
\hline Pre-pregnancy & 6 & $7.9(6.3-11.0)$ \\
\hline Trimester 1 & $15^{\dagger}$ & $8.8(5.5-12.4)$ \\
\hline Trimester 2 & $30^{\ddagger}$ & $10.0(7.1-13.7)$ \\
\hline Trimester 3 & $20^{\S}$ & $11.0(7.1-16.8)$ \\
\hline Delivery & 8 & $11.2(8.4-15.7)$ \\
\hline Postpartum & 12 & $10.3(4.3-13.8)$
\end{tabular}

† 1 participant had 2 levels within trimester 1 ; 9 participants had two levels within trimester 2;

$\S 2$ participants had two levels within trimester 3

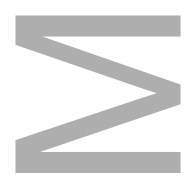

Table 3: Median adalimumab levels across pregnancy $(n=15)$

\begin{tabular}{|l|c|c|}
\hline & Number of observations & Median (IQR) adalimumab level $(\mu \mathrm{g} / \mathrm{mL})$ \\
\hline Pre-pregnancy & 2 & $10.4(10.0-10.8)$ \\
\hline Trimester 1 & 9 & $5.7(4.8-10.2)$ \\
\hline Trimester 2 & 12 & $5.2(4.0-6.8)$ \\
\hline Trimester 3 & 14 & $5.8(4.8-8.0)$ \\
\hline Delivery & 8 & $6.7(5.1-8.0)$ \\
\hline Postpartum & 8 & $7.2(4.3-9.7)$ \\
\hline
\end{tabular}

Table 4: Trough vedolizumab levels during pregnancy $(n=12)$

This article is protected by copyright. All rights reserved 


\begin{tabular}{|l|c|c|}
\hline Trimester 1 & 5 & $19.0(13.0-23.0)$ \\
\hline Trimester 2 & $16^{\dagger}$ & $15.1(8.6-21.7)$ \\
\hline Trimester 3 & 9 & $9.5(3.7-20.0)$ \\
\hline Delivery & $2^{\ddagger}$ & $5.5(1.1-9.9)$ \\
\hline
\end{tabular}

† 5 participants had two levels within trimester $2 ; \ddagger$ other delivery levels not trough

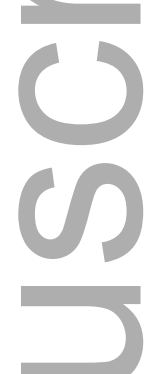

Table 5: Infant vedolizumab levels

\begin{tabular}{|c|c|c|c|}
\hline Infant & $\begin{array}{l}\text { Vedolizumab level at } \\
\text { delivery }(\mu \mathrm{g} / \mathrm{mL})\end{array}$ & $\begin{array}{l}\text { Vedolizumab level at } \\
6-9 \text { weeks }(\mu \mathrm{g} / \mathrm{mL})\end{array}$ & $\begin{array}{l}\text { Vedolizumab level at } \\
10-15 \text { weeks }(\mu \mathrm{g} / \mathrm{mL})\end{array}$ \\
\hline Patient 1 & 2.1 & 0.20 & 0.0 \\
\hline Patient 2 & 4.9 & 0.70 & Declined \\
\hline Patient 3 & 5.9 & 0.86 & Declined \\
\hline Patient 4 & 8.7 & 0.0 & NA \\
\hline Patient 5 & 1.0 & 0.0 & NA \\
\hline Patient 6 & 19.0 & - & 0.0 \\
\hline Patient 7 & 5.0 & 0.0 & NA \\
\hline Patient 8 & $4.1^{\dagger}$ & - & 0.0 \\
\hline Patient 9 & 2.5 & - & 0.0 \\
\hline Patient 10 & 4.4 & 0.50 & 0.0 \\
\hline Patient 11 & 9.0 & 0.65 & Declined \\
\hline Patient 12 & 13.0 & 4.40 & 1.9 (12 weeks) \\
\hline
\end{tabular}




\begin{tabular}{|l|c|c|c|}
\hline Patient 13 & 6.2 & Declined & Declined \\
\hline Patient 14 & 7.1 & - & $\mathbf{0 . 0}$ \\
\hline Patient 15 & $5.0^{+}$ & - & $\mathbf{0 . 0}$ \\
\hline Patient 16 & 1.9 & $\mathbf{0 . 0}$ & NA \\
\hline Patient 17 & 1.9 & Pending & \\
\hline
\end{tabular}

† venous sample collected (not cord blood)

Table 6: Pregnancy outcomes

\begin{tabular}{|c|c|c|c|c|}
\hline Median (IQR) orn (\%) & & $\begin{array}{l}\text { Anti-TNF } \\
n=38\end{array}$ & $\begin{array}{l}\text { Vedolizumab } \\
n=17\end{array}$ & p-value \\
\hline $\begin{array}{l}\text { Gestation at delivery } \\
\text { (weeks) }\end{array}$ & & 39 (38-39) & $38.5(38-39)$ & 0.34 \\
\hline Pre-term (<37 weeks) & Yes & $1(3 \%)$ & $2(12 \%)$ & 0.17 \\
\hline Birth weight (g) & & 3295 (3010-3650) & 3390 (2896-3470) & 0.67 \\
\hline $\begin{array}{l}\text { Low birth weight } \\
\text { (<2500g) }\end{array}$ & Yes & $3(8 \%)$ & $2(12 \%)$ & 0.64 \\
\hline Birth length $(\mathrm{cm})$ & & $50.25(49-52)$ & $50(48-51)$ & 0.48 \\
\hline Sex of baby & Boy & $18(47 \%)$ & $8(47 \%)$ & 0.98 \\
\hline$r$ & Girl & $20(53 \%)$ & $9(53 \%)$ & \\
\hline Mode of delivery & $\begin{array}{l}\text { Caesarean } \\
\text { section- } \\
\text { emergency }\end{array}$ & $9(24 \%)$ & $2(12 \%)$ & 0.42 \\
\hline & $\begin{array}{l}\text { Caesarean } \\
\text { section- elective }\end{array}$ & $12(32 \%)$ & $9(53 \%)$ & \\
\hline & Vaginal birth & $12(32 \%)$ & $5(29 \%)$ & \\
\hline
\end{tabular}




\begin{tabular}{|c|c|c|c|c|}
\hline & $\begin{array}{l}\text { Vaginal birth- } \\
\text { instrumental }\end{array}$ & $5(13 \%)$ & $1(6 \%)$ & \\
\hline APGAR score at 1 minute & & $9(9-9)$ & $9(9-9)$ & 0.23 \\
\hline $\begin{array}{l}\text { APGAR score at } 5 \\
\text { minutes }\end{array}$ & & $9(9-9)$ & $9(9-9)$ & 1.00 \\
\hline $\begin{array}{l}\text { Infant admitted to } \\
\text { neonatal intensive care }\end{array}$ & Yes & $4(11 \%)$ & $3(18 \%)$ & 0.46 \\
\hline $\begin{array}{l}\text { Congenital abnormality } \\
\text { at birth }\end{array}$ & Yes & $0(0 \%)$ & $1(6 \%)$ & 0.26 \\
\hline Gestational diabetes & Yes & $4(11 \%)$ & $3(18 \%)$ & 0.59 \\
\hline Pre-eclamps & Yes & $3(8 \%)$ & $1(6 \%)$ & 0.78 \\
\hline $\begin{array}{l}\text { Iron infusion during } \\
\text { pregnancy }\end{array}$ & Yes & $10(26 \%)$ & $13(76 \%)$ & $<0.001$ \\
\hline Smoking history & Yes, daily & $1(3 \%)$ & $0(0 \%)$ & 0.38 \\
\hline & $\begin{array}{l}\text { Yes, but not } \\
\text { every day }\end{array}$ & $0(0 \%)$ & $1(6 \%)$ & \\
\hline $\begin{array}{l}\text { Alcohol during } \\
\text { pregnancy }\end{array}$ & Yes & $4(11 \%)$ & $0(0 \%)$ & 0.19 \\
\hline
\end{tabular}

Table 7: Infant outcomes reported following intrauterine vedolizumab exposure up to three months of age $(n=16)$

\begin{tabular}{|c|c|c|c|}
\hline Median (IQR) or $n(\%)$ & & $\begin{array}{c}6 \text { weeks } \\
n=16\end{array}$ & $\begin{array}{c}3 \text { months } \\
n=16\end{array}$ \\
\hline Infant growth - centile according to & Below 10 th centile & $2(12 \%)$ & $1(6 \%)$ \\
\hline
\end{tabular}




\begin{tabular}{|l|l|c|c|}
\hline \multirow{2}{*}{ weight } & Between $10^{\text {th }}-90^{\text {th }}$ centile & $13(81 \%)$ & $11(69 \%)$ \\
\cline { 2 - 4 } & Above 90th centile & $1(6 \%)$ & $1(6 \%)$ \\
\cline { 2 - 4 } & Unknown & $0(0 \%)$ & $3(19 \%)$ \\
\hline Any reported infections & No & $16(100 \%)$ & $16(100 \%)$ \\
\hline Chronic diseases or medical conditions & Yes & $2(12 \%)$ & $1(6 \%)$ \\
\hline Adverse reactions to vaccinations & Yes & $0(0 \%)$ & $0(0 \%)$ \\
\hline Allergies & Yes & $0(0 \%)$ & $2(12 \%)$ \\
\hline Breastfeeding & Yes & $9(56 \%)$ & $9(56 \%)$ \\
\hline
\end{tabular}

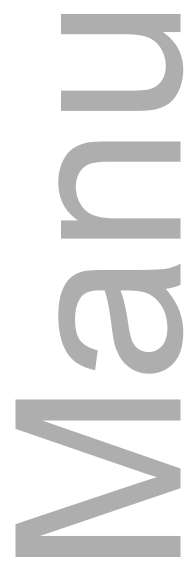

Figure legends

Figure 1: Individual trough infliximab levels during pregnancy

Figure 2: Median trough infliximab levels across pregnancy

Figure 3: Individual adalimumab levels during pregnancy

Figure 4: Median adalimumab levels across pregnancy

Figure 5: Individual trough vedolizumab levels during pregnancy 
Figure 6: Median trough vedolizumab levels in pregnancy

Figure 7: Correlation between maternal and infant vedolizumab levels at delivery

Figure 8: Correlation between infant vedolizumab level at delivery and weeks since last intrapartum infusion

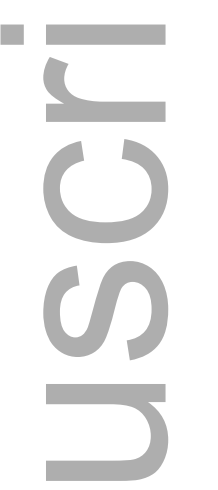

Appendix 1

PICCOLO Study Group collaborators who assisted with recruitment of patients:

Susan Connor

Liverpool Hospital, Liverpool, Australia

Ilana Gory

Alfred Health, Melbourne, Australia

Nik S Ding

St Vincent's Hospital Melbourne, Australia

Emily Prewett

Barwon Health, Geelong, Australia

Simon Ghaly

St Vincent's Hospital, Sydney, Australia

Antony Friedman

This article is protected by copyright. All rights reserved 
Alfred Health, Melbourne, Australia

Mayur Garg

Eastern Health, Melbourne, Australia; Northern Health, Melbourne Australia<smiles>[CH]</smiles>

Julia Dingley

Wyoming, New South Wales, Australia

Lena Thin

Fiona Stanley Hospital, Perth, Australia

Neal Martin

Princess Alexandra Hospital, Brisbane, Australia

Yoon-Kyo An

Mater Hospital, Brisbane, Australia

Krupa Krishnaprasad

St Vincent's Hospital Melbourne, Australia

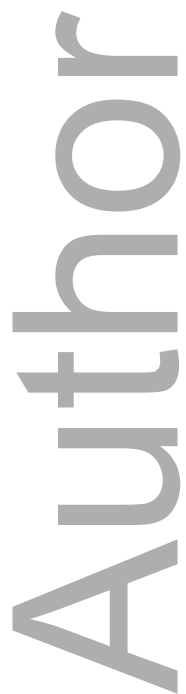

This article is protected by copyright. All rights reserved 
Figure 1: Individual trough infliximab levels during pregnancy
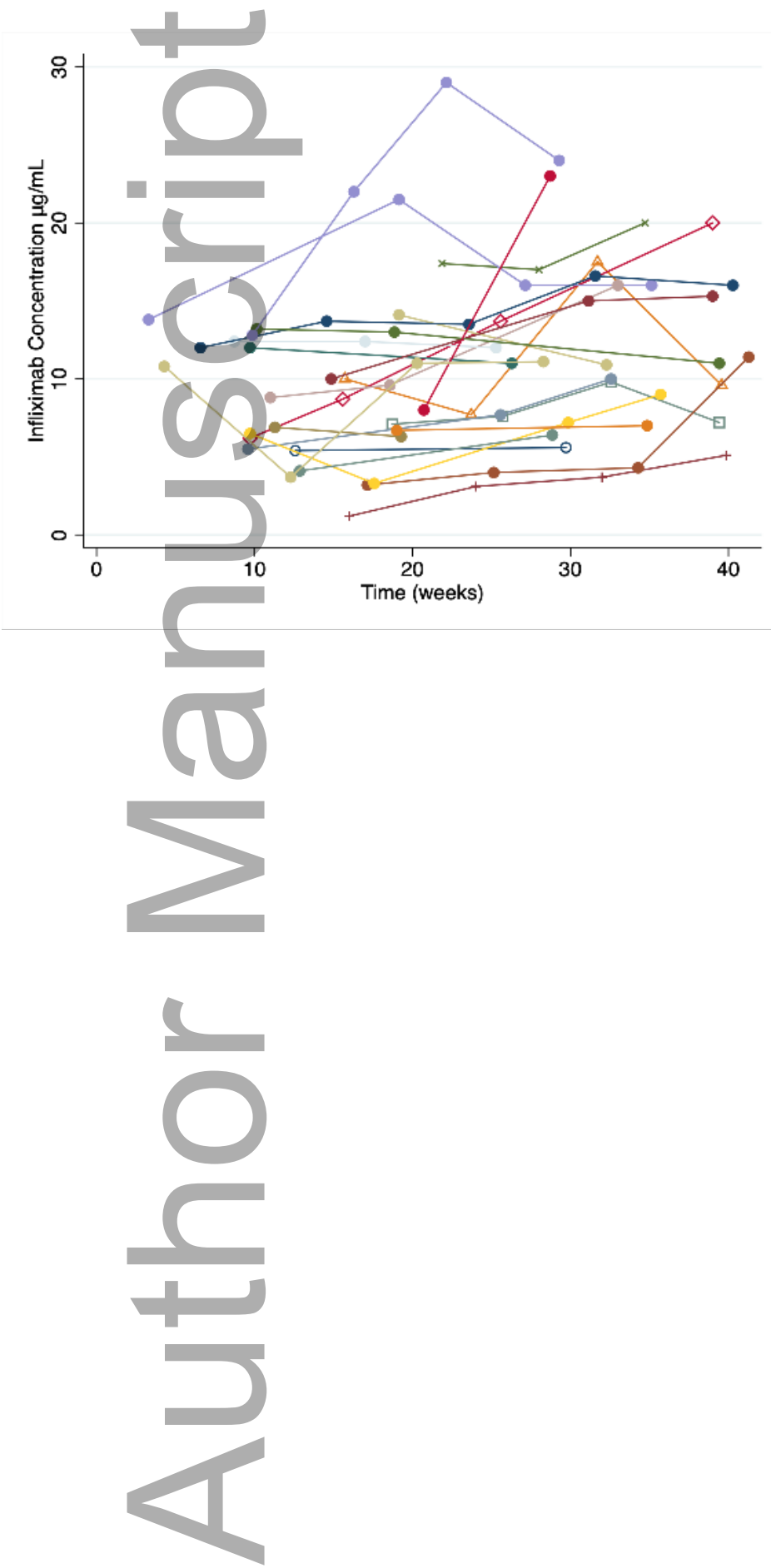

This article is protected by copyright. All rights reserved 


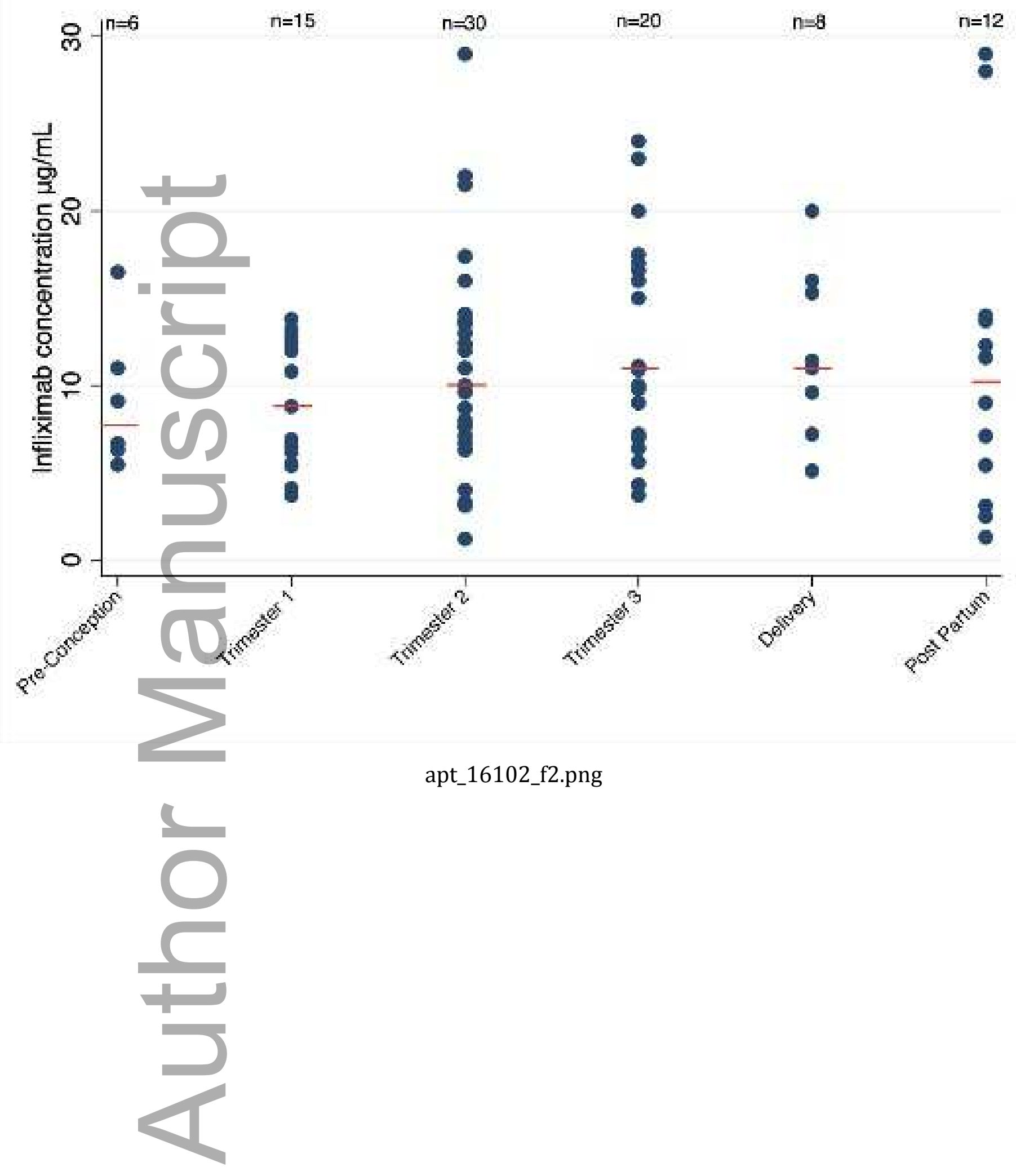

This article is protected by copyright. All rights reserved 
Figure 3: Individual adalimumab levels during pregnancy
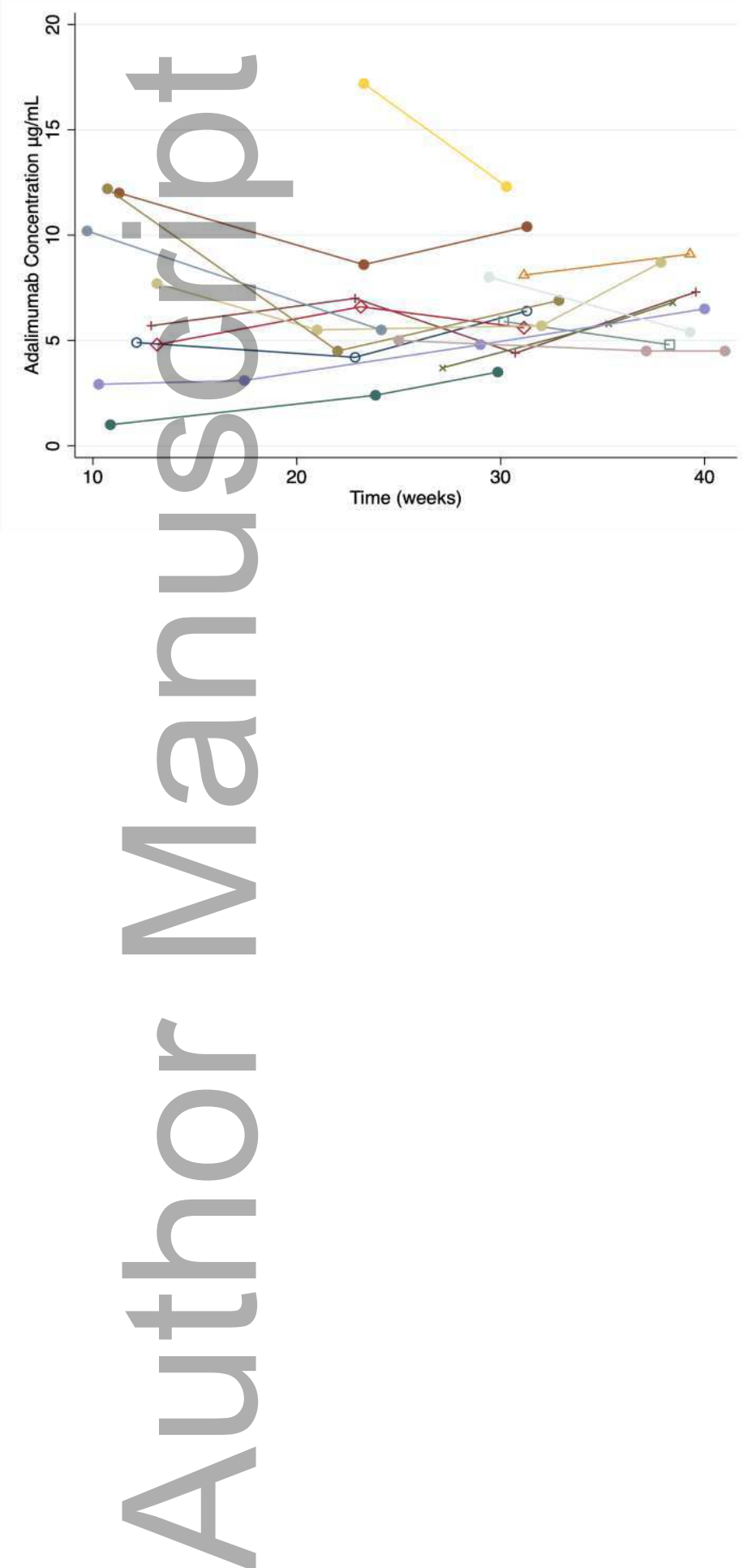

This article is protected by copyright. All rights reserved 


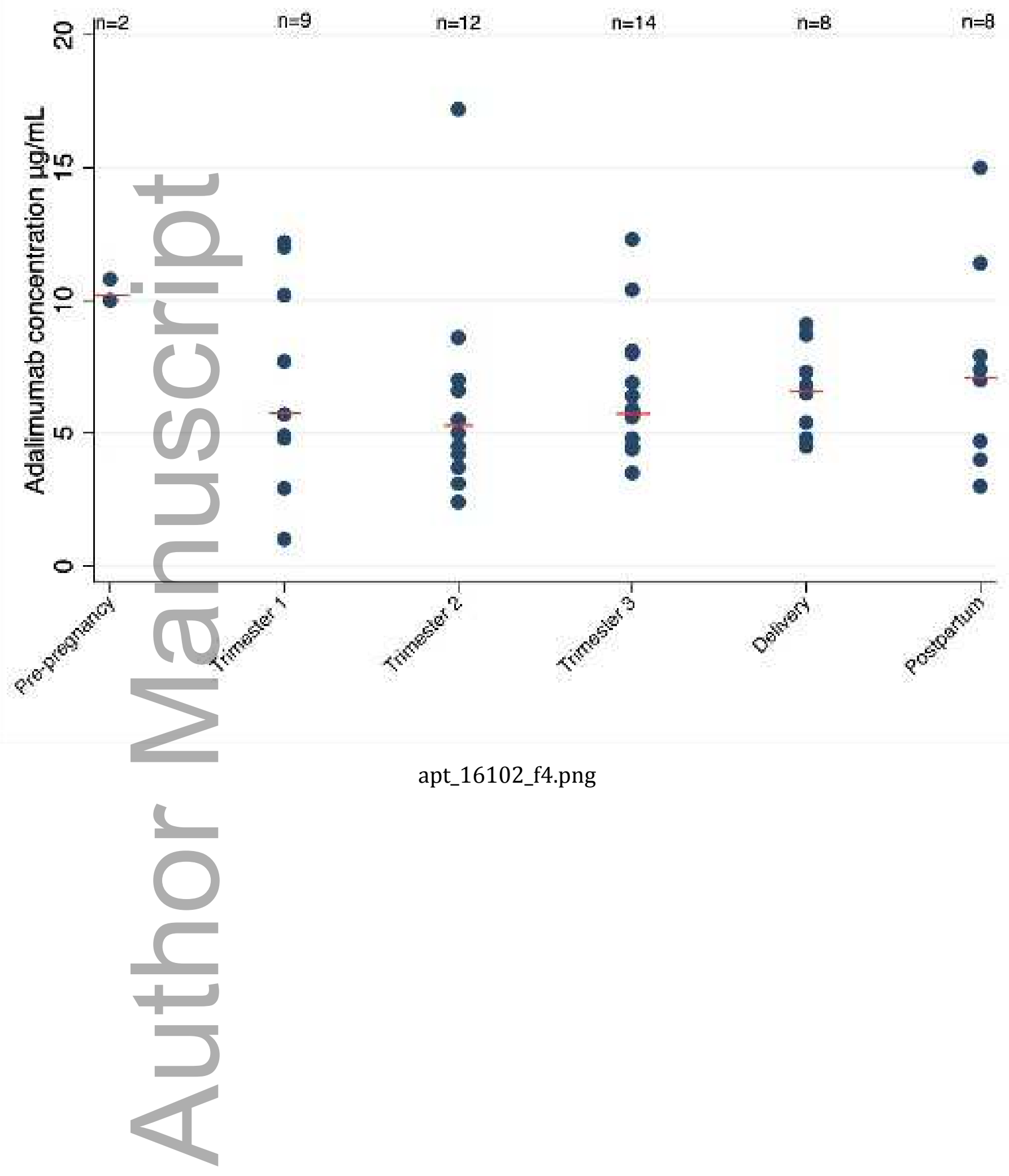

This article is protected by copyright. All rights reserved 
Figure 5: Individual trough vedolizumab levels during pregnancy
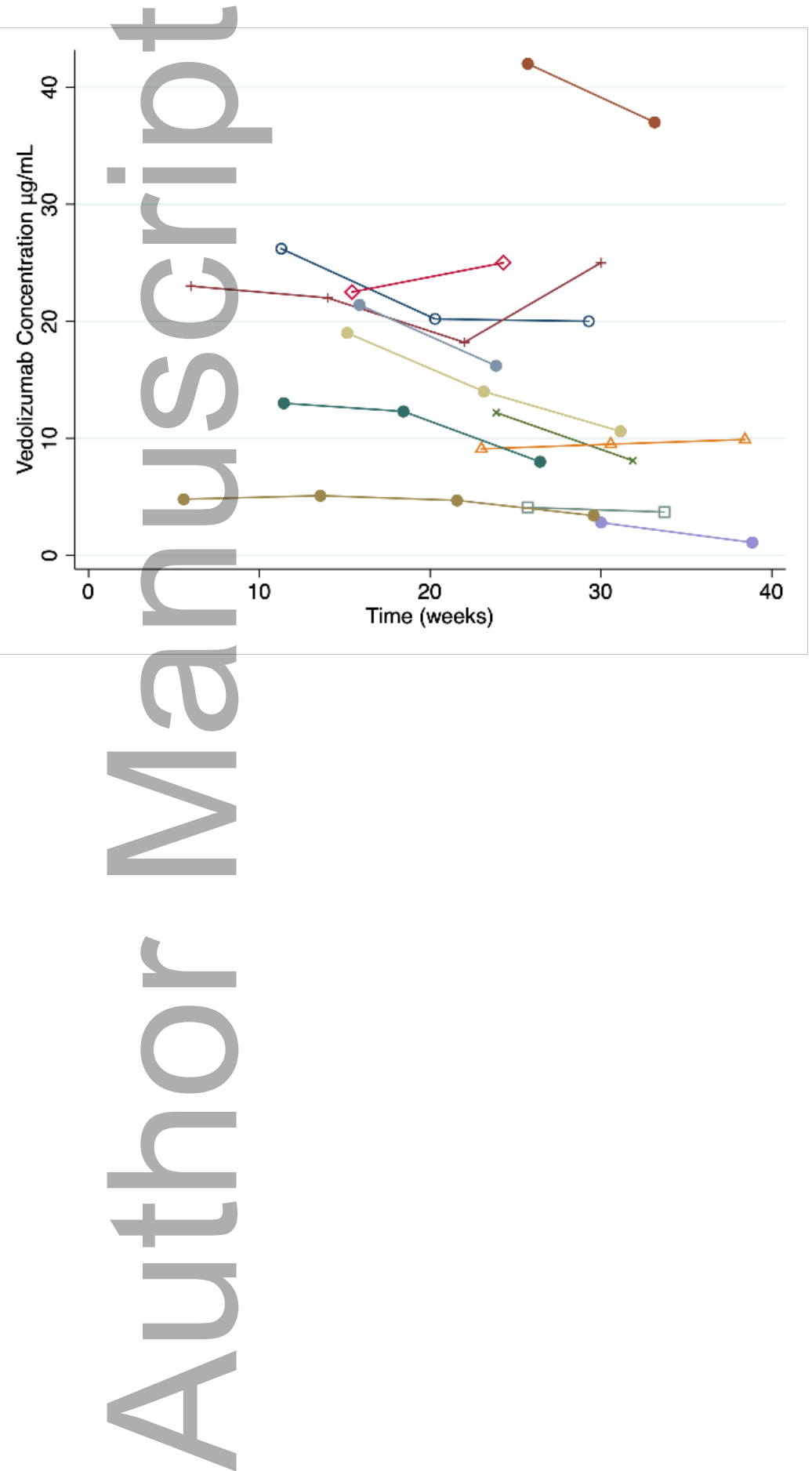

This article is protected by copyright. All rights reserved 


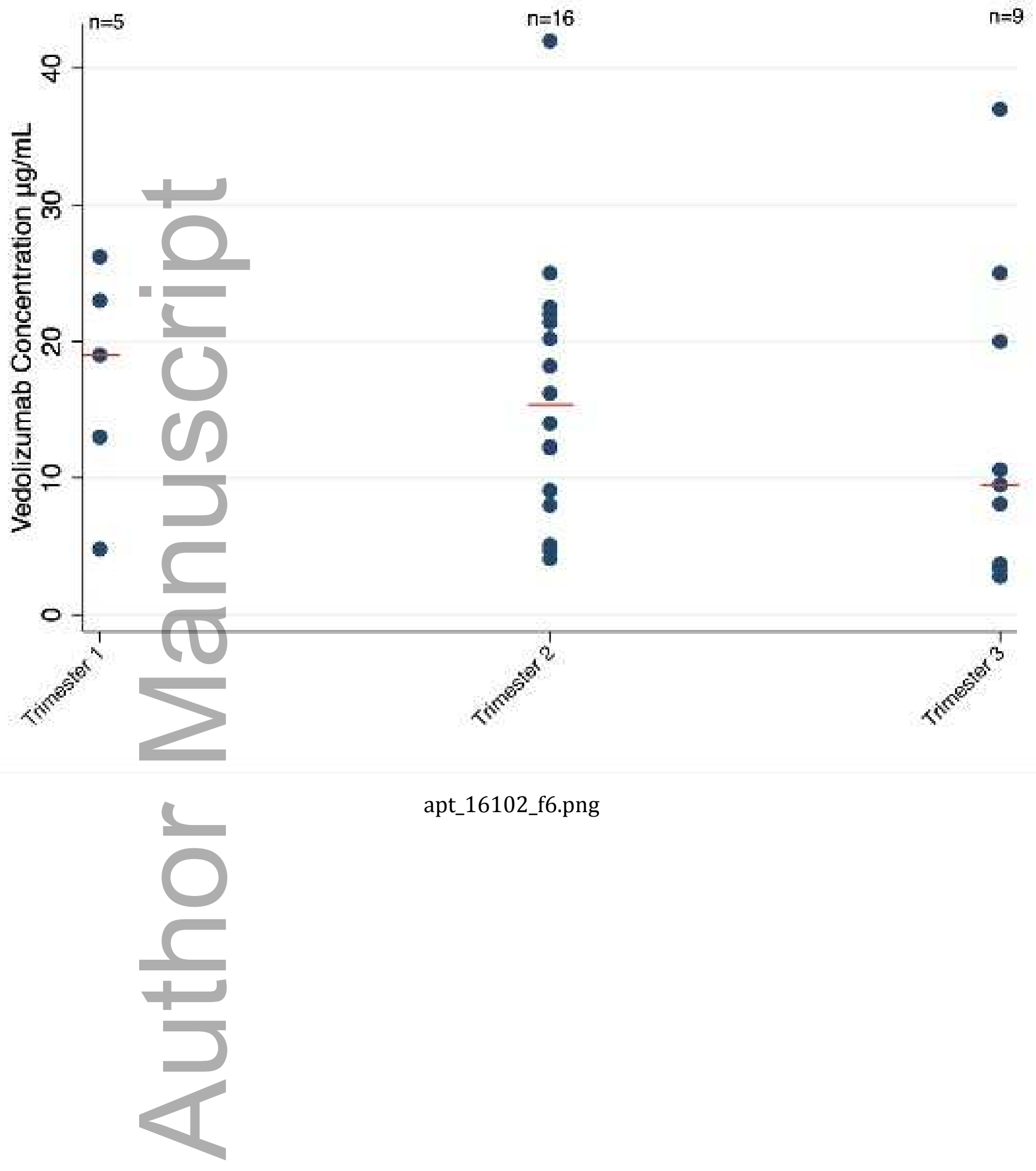

This article is protected by copyright. All rights reserved 
Figure 7: Correlation between maternal and infant vedolizumab levels at delivery
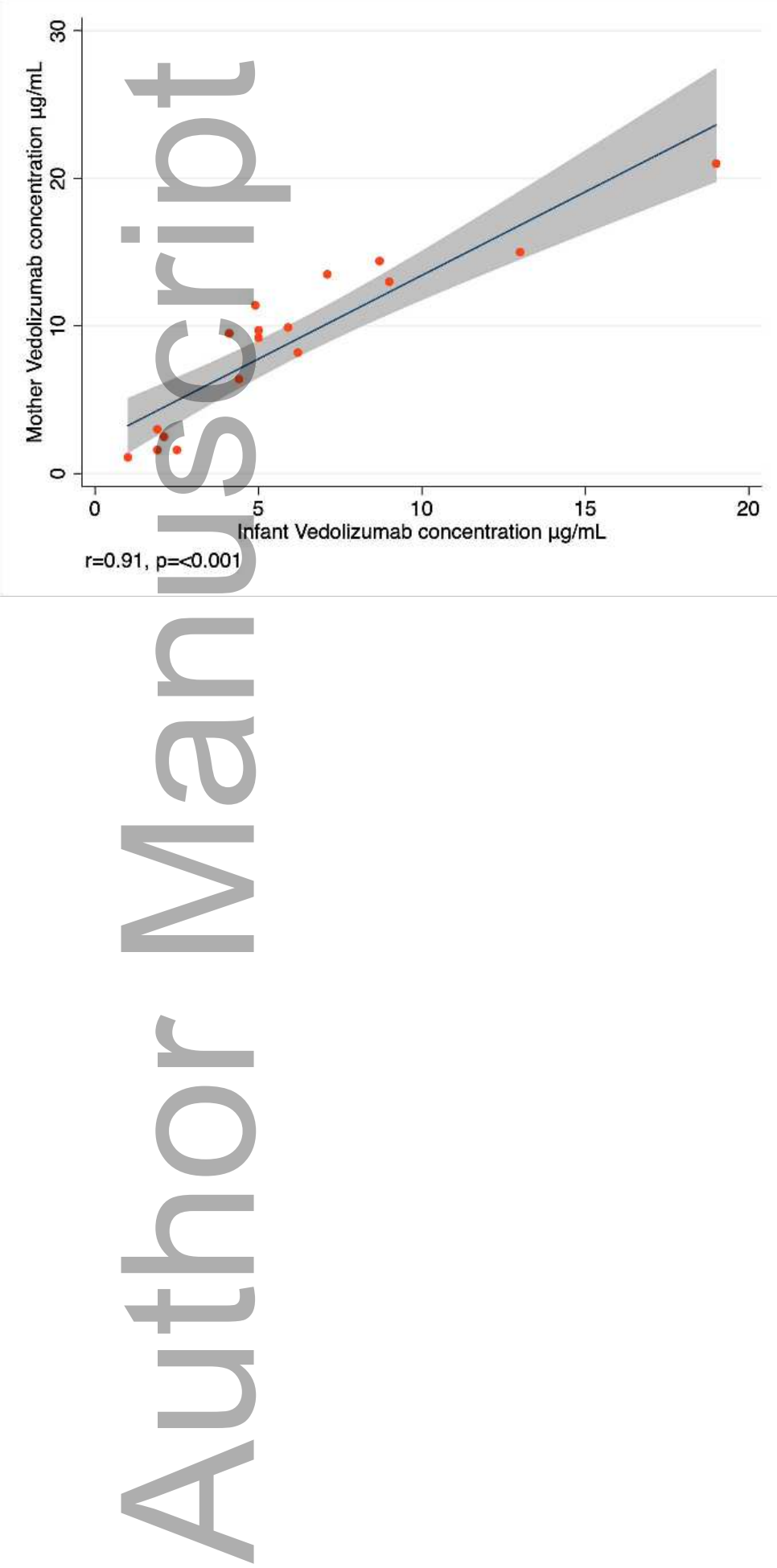

This article is protected by copyright. All rights reserved 
Figure 8: Correlation between infant vedolizumab level at delivery and weeks since last intrapartum infusion
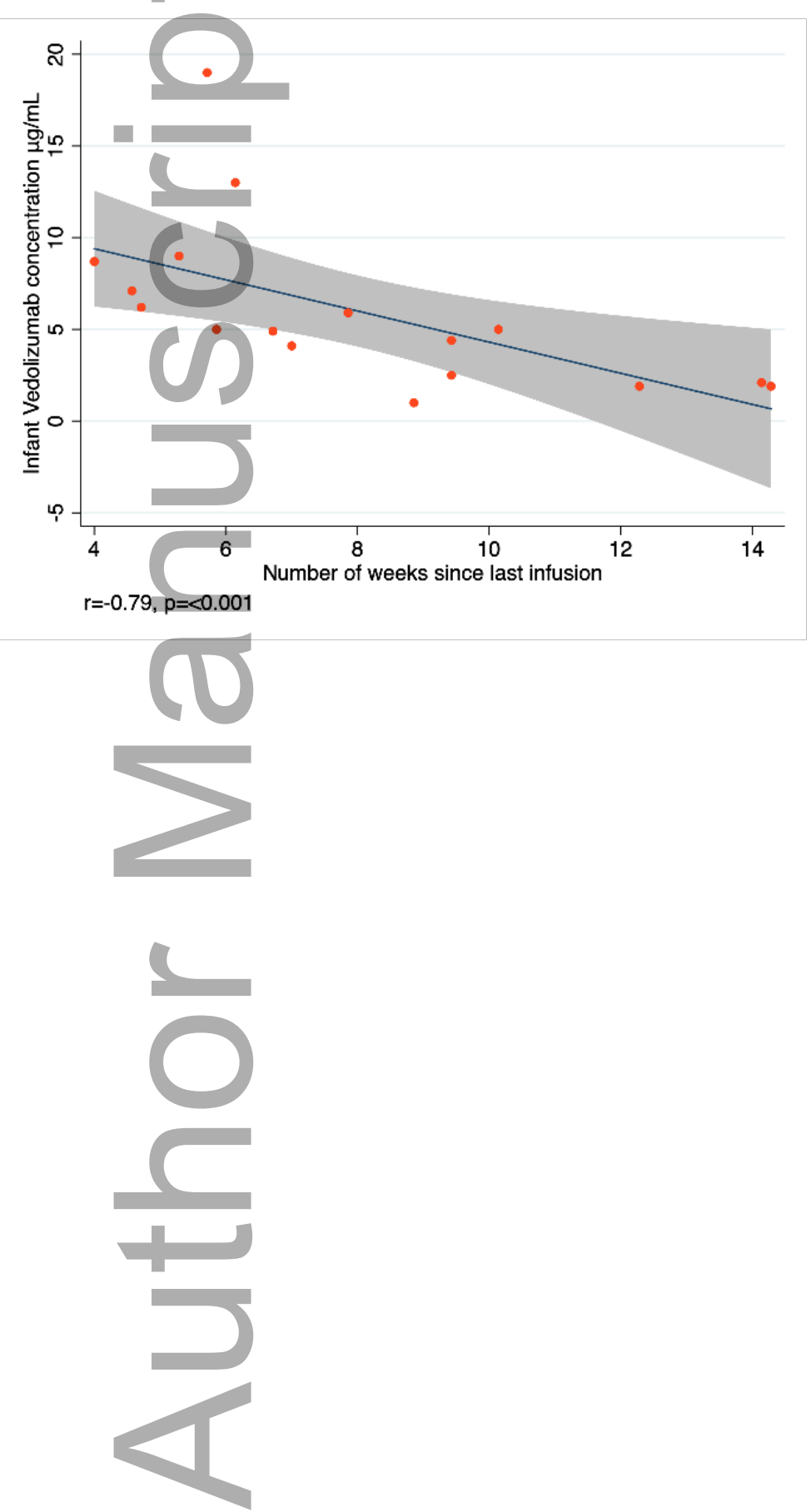

This article is protected by copyright. All rights reserved 


\section{University Library}

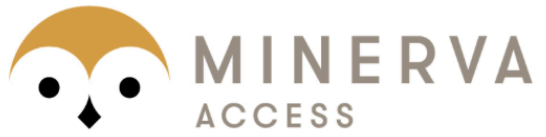

A gateway to Melbourne's research publications

Minerva Access is the Institutional Repository of The University of Melbourne

\section{Author/s:}

Flanagan, E;Gibson, PR;Wright, EK;Moore, GT;Sparrow, MP;Connell, W;Kamm, MA;Begun, J;Christensen, B;De Cruz, P;Shelton, E;Dowling, D;Andrews, JM;Brown, SJ;Niewiadomski, O;Ward, MG;Rosella, O;Rosella, G;Kiburg, KV;Ross, AL;Bell, SJ

Title:

Infliximab, adalimumab and vedolizumab concentrations across pregnancy and vedolizumab concentrations in infants following intrauterine exposure

Date:

2020-11

\section{Citation:}

Flanagan, E., Gibson, P. R., Wright, E. K., Moore, G. T., Sparrow, M. P., Connell, W., Kamm, M. A., Begun, J., Christensen, B., De Cruz, P., Shelton, E., Dowling, D., Andrews, J. M., Brown, S. J., Niewiadomski, O., Ward, M. G., Rosella, O., Rosella, G., Kiburg, K. V. ,... Bell, S. J. (2020). Infliximab, adalimumab and vedolizumab concentrations across pregnancy and vedolizumab concentrations in infants following intrauterine exposure. ALIMENTARY PHARMACOLOGY \& THERAPEUTICS, 52 (10), pp.1551-1562. https://doi.org/10.1111/ apt.16102.

Persistent Link:

http://hdl.handle.net/11343/276362 